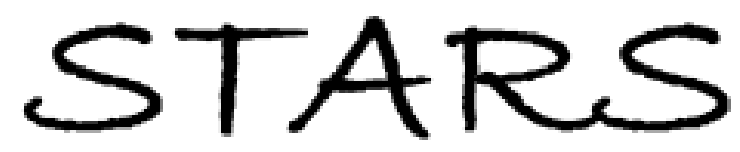

University of Central Florida

STARS

$1-1-2007$

\title{
Phonon characteristics and photoluminescence of bamboo structured silicon-doped boron nitride multiwall nanotubes
}

Shifeng Xu

Yi Fan

Jingsong Luo

Ligong Zhang

Wenquan Wang

See next page for additional authors

Find similar works at: https://stars.library.ucf.edu/facultybib2000

University of Central Florida Libraries http://library.ucf.edu

This Article is brought to you for free and open access by the Faculty Bibliography at STARS. It has been accepted for inclusion in Faculty Bibliography 2000 s by an authorized administrator of STARS. For more information, please contactSTARS@ucf.edu.

\section{Recommended Citation}

Xu, Shifeng; Fan, Yi; Luo, Jingsong; Zhang, Ligong; Wang, Wenquan; Yao, Bin; and An, Linan, "Phonon characteristics and photoluminescence of bamboo structured silicon-doped boron nitride multiwall nanotubes" (2007). Faculty Bibliography 2000s. 7814.

https://stars.library.ucf.edu/facultybib2000/7814

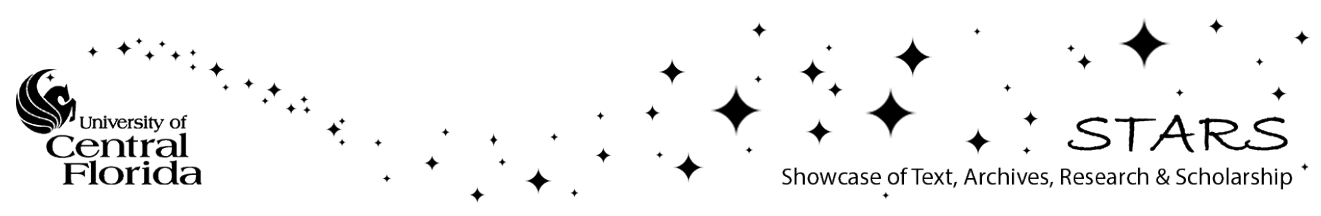




\section{Authors}

Shifeng Xu, Yi Fan, Jingsong Luo, Ligong Zhang, Wenquan Wang, Bin Yao, and Linan An 


\section{Phonon characteristics and photoluminescence of bamboo structured silicon-doped boron nitride multiwall nanotubes}

Cite as: Appl. Phys. Lett. 90, 013115 (2007); https://doi.org/10.1063/1.2429904

Submitted: 28 March 2006 . Accepted: 30 November 2006 . Published Online: 05 January 2007

Shifeng Xu, Yi Fan, Jingsong Luo, Ligong Zhang, Wenquan Wang, Bin Yao, and Linan An

\section{ARTICLES YOU MAY BE INTERESTED IN}

Synthesis of boron nitride nanotubes from carbon nanotubes by a substitution reaction Applied Physics Letters 73, 3085 (1998); https://doi.org/10.1063/1.122680

Electrical transport properties of the Si-doped cubic boron nitride thin films prepared by in situ cosputtering

Journal of Applied Physics 109, 023716 (2011); https://doi.org/10.1063/1.3544065

Electric conductivity of boron nitride thin films enhanced by in situ doping of zinc Applied Physics Letters 89, 112124 (2006); https://doi.org/10.1063/1.2354009
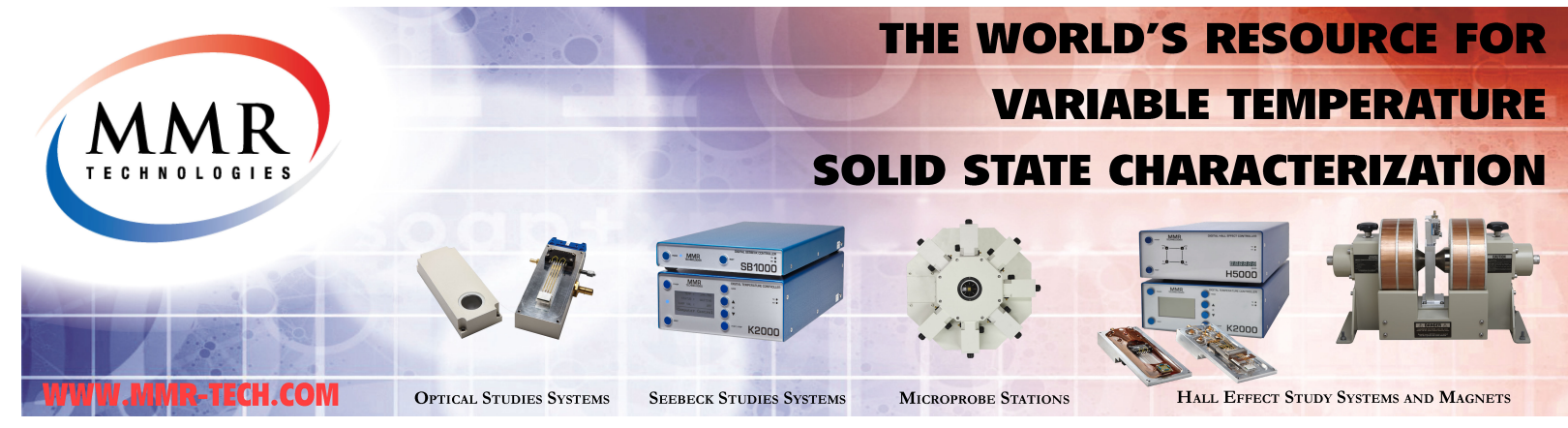


\title{
Phonon characteristics and photoluminescence of bamboo structured silicon-doped boron nitride multiwall nanotubes
}

\author{
Shifeng $\mathrm{Xu}$, Yi Fan, Jingsong Luo, and Ligong Zhang ${ }^{\mathrm{a}, \mathrm{b})}$ \\ Laboratory of Excited State Processes, Changchun Institute of Optics, Fine Mechanics and Physics, \\ Chinese Academy of Sciences, Changchun 130033, China \\ Wenquan Wang and Bin Yao \\ Department of Physics, Jilin University, Changchun 130023, China \\ Linan $\mathrm{An}^{\mathrm{a}), \mathrm{c})}$ \\ Advanced Materials Processing and Analysis Center, University of Central Florida, Orlando, Florida 32816
}

(Received 28 March 2006; accepted 30 November 2006; published online 5 January 2007)

\begin{abstract}
Bamboo structured silicon-doped boron nitride multiwall nanotubes are synthesized via catalyst-assisted pyrolysis of a boron-containing polymeric precursor. The nanotubes are characterized using transmission electron microscopy, $\mathrm{x}$-ray diffraction, Raman, and Fourier-transformed infrared spectroscope. The results suggest that the Si dopants cause significant changes in the structure and phonon characteristics of the nanotubes as compared to pure boron nitride nanotubes. A broad photoluminescence band ranging between 500 and $800 \mathrm{~nm}$ is observed from the nanotubes, which is attributed to $\mathrm{Si}$ dopants. Study on temperature dependence of emission intensity suggests that the thermal activation energy of the nonradiative recombination process is 35 meV. (c) 2007 American Institute of Physics. [DOI: 10.1063/1.2429904]
\end{abstract}

Boron nitride nanotubes (BNNTs), which are thermally stable and chemically inert, have attracted extensive attention in recent years for their potential applications in nanoelectronic and nanophotonic devices. ${ }^{1-3}$ Theoretical calculation predicted that where the diameter of BNNTs is larger than a certain value ( $\sim 10 \mathrm{~B}-\mathrm{N}$ units), band gaps of the tubes are approximately equal to that of bulk hexagonal $\mathrm{BN}$ $(h-\mathrm{BN})$, and almost independent of their radius and chirality, and whether they are single or multiwalled. ${ }^{4,5}$ The electronic structures of BNNTs can be tailored by doping. Previous studies on carbon-doped BNNTs demonstrated that their electronic properties were primarily determined by composition. ${ }^{6,7}$ Phonon characteristics and luminescence properties of BNNTs have also been studied to obtain a better understanding of their properties and detailed structures. ${ }^{8,9}$ However, all previous works were focused on either pure or carbon-doped BNNTs.

In this letter, we report studies on Si-doped multiwall boron nitride nanotubes (Si-BNNTs). While both silicon and carbon belong to the same IV group, silicon has no $s p^{2}$ hybridization. Consequently, a fundamentally different effect is expected between silicon doping and carbon doping.

The Si-BNNTs were synthesized by pyrolysis of a boron-modified polymeric precursor in the presence of $\mathrm{FeCl}_{2}$ as the catalyst. ${ }^{10}$ The precursor was first mixed with 5 wt $\%$ $\mathrm{FeCl}_{2}$ powder using high energy ball milling. The mixture was then annealed in a tube furnace at $1350{ }^{\circ} \mathrm{C}$ for $3 \mathrm{~h}$ in $\mathrm{N}_{2}$. During the annealing, the precursor was first decomposed to amorphous silicoboron carbonitride powder at $1000{ }^{\circ} \mathrm{C},{ }^{11}$ which was then reacted with the Fe to form $\mathrm{Si}-$ $\mathrm{C}-\mathrm{B}-\mathrm{Fe}$ liquid alloy droplets at temperatures higher than the eutectic point of the system. The nanotubes were precipitated and grew from the droplets through reaction between $B$ in

\footnotetext{
a) Authors to whom correspondence should be addressed.

b)Electronic mail: lg_zhang@yahoo.com

${ }^{\mathrm{c}}$ Electronic mail: lan@mail.ucf.edu
}

the droplets and $\mathrm{N}_{2}$ in the environment. Figure 1(a) shows a typical transmission electron microscopy (TEM) image of the bamboo structured Si-BNNTs, which are 80-200 $\mathrm{nm}$ in diameter and up to a few micrometers in length. ${ }^{10}$ Energydispersive $\mathrm{X}$-ray spectroscopy analysis reveals that the nanotubes consist of uniformly distributed $\mathrm{B}, \mathrm{N}$, and $\mathrm{Si}$ with the B-to-N-to-Si ratio of 1:1:0.06. ${ }^{10}$ Figures $1(\mathrm{~b})-1(\mathrm{~d})$ are high

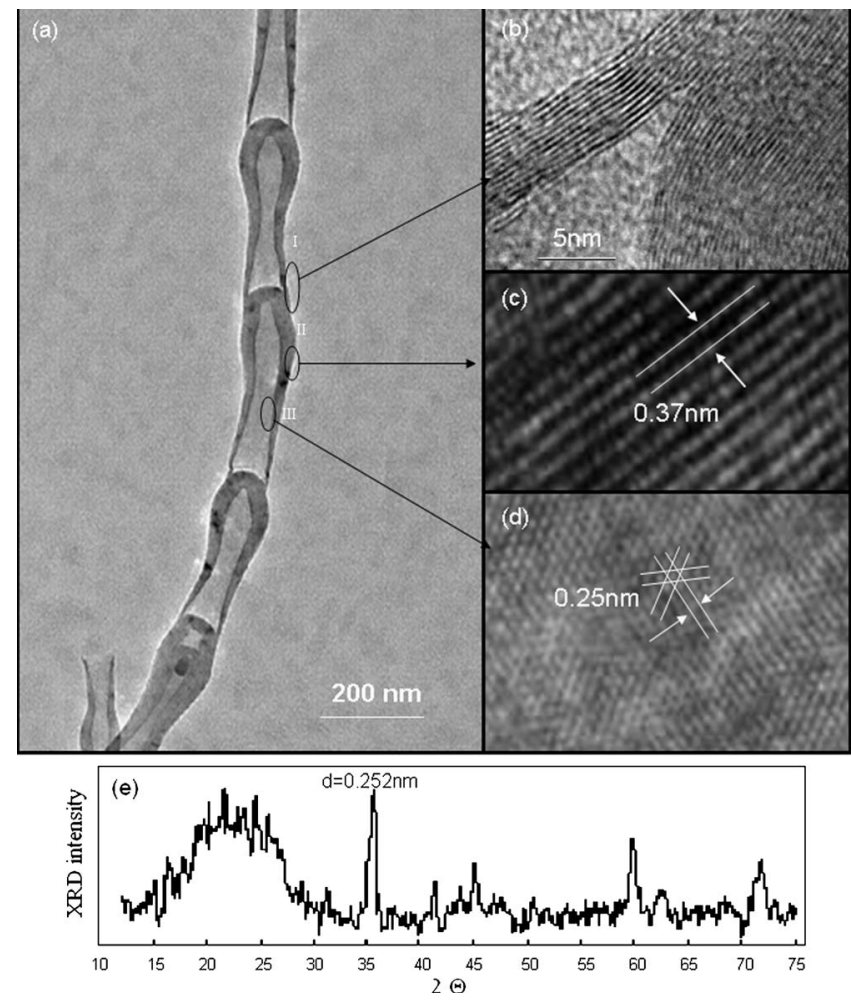

FIG. 1. (a) TEM image of the bamboo structured Si-BNNTs: [(b)-(d)] HRTEM images of the areas marked in (a) showing the detailed structure of the Si-BNNTs: (e) XRD pattern of the Si-BNNTs. 


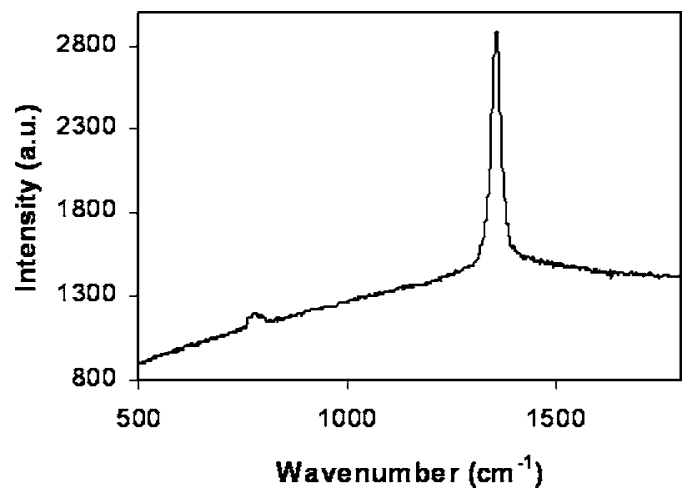

FIG. 2. Room-temperature Raman spectrum of the Si-BNNTs.

resolution TEM (HRTEM) images recorded from the areas marked in Fig. 1(a), showing the detailed structure of the Si-BNNTs. The interplane spacing measured from the HRTEM image is $\sim 0.37 \mathrm{~nm}$ [Fig. 1(c)], which is larger than that measured in bulk hexagonal/rhombohedral $\mathrm{BN}^{12}$ and stoichiometric BN nanotubes of $0.333 \mathrm{~nm} .{ }^{13}$ The in-plane $[(10 \overline{0})$ planes] lattice spacing measured from the HRTEM image is $\sim 0.25 \mathrm{~nm}$ [Fig. 1(d)], which is consistent with that measured from the x-ray diffraction (XRD) pattern [Fig. 1(e)]. This value is larger than that measured from pure BN nanotubes $(0.22 \mathrm{~nm}){ }^{14,15}$ The larger values of fringe spacing are likely due to the silicon doping.

Raman spectrum of the Si-BNNTs was collected using an UV-lamp spectroscope with a $30 \mathrm{~mW} \mathrm{Ar}{ }^{+}$laser $(488 \mathrm{~nm})$ as the excitation source (Fig. 2). The dominant peak near $1357 \mathrm{~cm}^{-1}$ is attributed to the well-known in-plane counterphase $\mathrm{B}-\mathrm{N}$ vibration mode $\left(E_{2 g}\right) .{ }^{16,17}$ The mode was previously observed for single-crystalline bulk $h$-BN at $1366 \mathrm{~cm}^{-1} .8,18$ Theoretical studies ${ }^{19-21}$ predicted a curvatureinduced softening for the $E_{2 g}$ mode when $h$-BN sheets were rolled up into nanotubes. About a $2 \mathrm{~cm}^{-1}$ downward shift was observed in high-purity BNNTs of $50 \mathrm{~nm}$ in diameter. ${ }^{9}$ Thereby, the curvature-induced softening by itself cannot account for the current shift $\left(\sim 9 \mathrm{~cm}^{-1}\right)$ since the curvature (tube diameter and cap area) of the current Si-BNNTs is relatively large. Here we attribute the shift to $\mathrm{Si}$ doping. The size (larger than $\mathrm{B}$ ) and relatively high concentration of $\mathrm{Si}$ dopants in the Si-BNNTs could cause an increase in average bond length and a disturbance in an otherwise perfect BN structure, thus leading to a significant softening effect. It is interesting to note that the effect of $\mathrm{Si}$ doping is different from $\mathrm{C}$ doping that caused the peak $2.1 \mathrm{~cm}^{-1}$ blueshift compared to bulk $h$-BN. ${ }^{8}$ The full width at half maximum of the peak is about $28 \mathrm{~cm}^{-1}$, which is remarkably wider than that observed in single-crystalline bulk $h$-BN $\left(8 \mathrm{~cm}^{-1}\right){ }^{18}$ The value is also wider than those observed in pure BNNTs $\left(\sim 13 \mathrm{~cm}^{-1}\right)^{9}$ and C-doped BNNTs $\left(\sim 18 \mathrm{~cm}^{-1}\right) .{ }^{8}$ The value is close to the upper end observed in chemical vapor deposition $h$-BN $\left(16-30 \mathrm{~cm}^{-1}\right),{ }^{16,22}$ which is characterized by a large amount of defects. Therefore, the current peak broadening is likely due to the $\mathrm{Si}$ doping and defects, such as partial/bent walls observed in the Si-BNNTs.

Fourier transformation infrared (FTIR) spectrum of the Si-BNNTs was recorded using a Bio-Rad FTS-3000 FTIR spectroscope (Fig. 3). The spectrum consists of four dominant peaks at $818,1241,1389$, and $1545 \mathrm{~cm}^{-1}$, and a pronounced shoulder at $1120 \mathrm{~cm}^{-1}$. The peak at $818 \mathrm{~cm}^{-1}$,

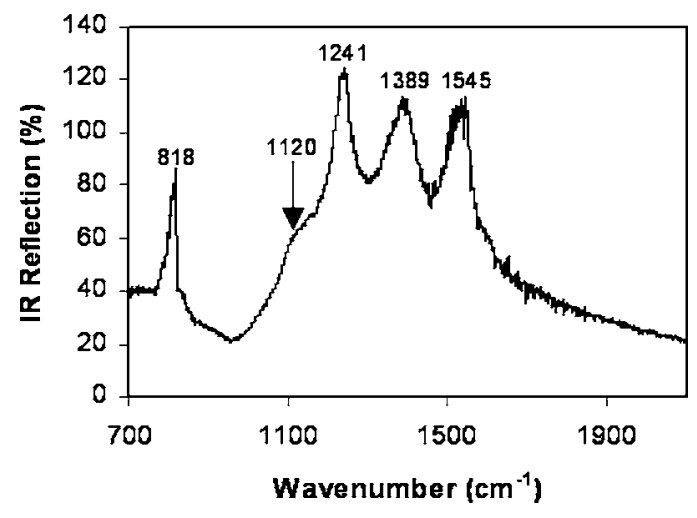

FIG. 3. Room-temperature FTIR spectrum of the Si-BNNTs.

which has an asymmetric shape with a peak at $818 \mathrm{~cm}^{-1}$ and a shoulder at $780 \mathrm{~cm}^{-1}$, can be assigned to the out-of-plane $A_{2 u}$ mode with transverse optical (TO)-longitudinal optical (LO) splitting. ${ }^{9,22,23}$ The position of the peak at $1389 \mathrm{~cm}^{-1}$ is higher than the in-plane $E_{1 u}(\mathrm{TO})$ mode observed in the pyrolytic $h$-BN $\left(1367 \mathrm{~cm}^{-1}\right),{ }^{22}$ the polycrystalline bulk $h$-BN $\left(1377 \mathrm{~cm}^{-1}\right),{ }^{23}$ and pure BNNTs [1366 (Ref. 9) and $1372 \mathrm{~cm}^{-1}$ (Ref. 23)], but lower than that in $h$-BN monolayers epitaxially deposited on metal surfaces $\left(1395 \mathrm{~cm}^{-1}\right),{ }^{24}$ which showed a buckled structure with some $s p^{3}$ admixture. Considering the $s p^{3}$ hybridization of Si dopants and the curvature in the cap area, the peak at $1389 \mathrm{~cm}^{-1}$, which shows an asymmetric shape with a peak at $1389 \mathrm{~cm}^{-1}$ and a shoulder at $1358 \mathrm{~cm}^{-1}$, can be attributed to the $E_{1 u}(\mathrm{TO})$ mode from the cap area $\left(1358 \mathrm{~cm}^{-1}\right)$ and from the wall area $\left(1389 \mathrm{~cm}^{-1}\right)$ of the bamboo structure. The softening effect is likely from the Si doping, similar to the Raman-active mode discussed above. Previous studies on pure BNNTs suggested that the peak near $1540 \mathrm{~cm}^{-1}$ is from the softened $E_{1 u}(\mathrm{LO})$ $\left(1610 \mathrm{~cm}^{-1}\right.$ in pyrolytic $h$-BN without softening $\left.{ }^{22}\right)$ due to the curvature effect. ${ }^{23}$ We can attribute the peak at $1545 \mathrm{~cm}^{-1}$ to the same origin. The origin of the peak at $1241 \mathrm{~cm}^{-1}$ and the shoulder at $1120 \mathrm{~cm}^{-1}$ in the FTIR spectrum (Fig. 3), which have not been observed previously in $h$-BN materials, is not clear to us at this moment. It is suspected that they are related to the Si doping, which have $s p^{3}$ hybridization.

The photoluminescence (PL) spectrum of the Si-BNNTs was measured under the excitation of an $\mathrm{Ar}^{+}$laser $(488 \mathrm{~nm})$. Figure 4(a) shows a typical PL spectrum obtained at $300 \mathrm{~K}$, which shows an intense broad emission band from 500 to $800 \mathrm{~nm}$ (sharp peaks at the high and low energy sides are due to Raman scattering). As mentioned previously, the band gaps of the BNNTs are approximately equal to that of bulk $h$-BN and independent of their radius and chirality when the tubes are large enough. ${ }^{4,5}$ Previous study on the cathode luminescence of pure multiwall BNNTs of $\sim 50 \mathrm{~nm}$ revealed an emission peak at $3.3 \mathrm{eV}$ with a shoulder at $4.1 \mathrm{eV} .{ }^{9} \mathrm{Wu}$ et al. reported a wide PL peak ranging between 3.5 and $4.2 \mathrm{eV}$ centered at $4.02 \mathrm{eV}$ from C-doped BNNTs. ${ }^{8}$ Here we tentatively attribute the PL to Si doping. Si atoms have one extra electron as compared to $\mathrm{B}$, which should results in a donor level within the band gap. In addition, point defects associated with $\mathrm{Si}$ and/or $\mathrm{N}$ can further modify the energy levels within the band gap, as in silicon nitride materials. ${ }^{25}$

The temperature dependence of PL was measured in a temperature range of $84-300 \mathrm{~K}$. The position and shape of 

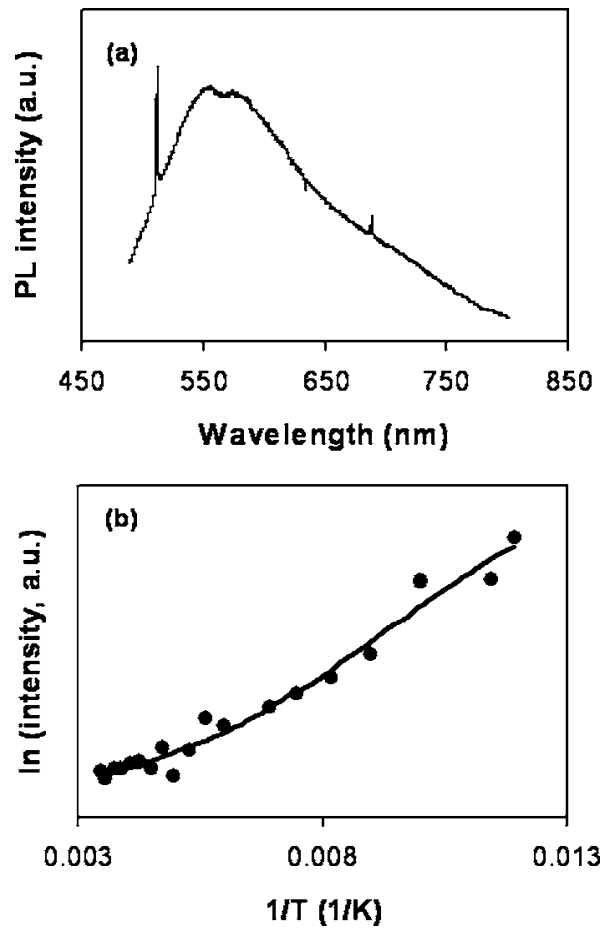

FIG. 4. (a) Room-temperature PL spectrum of the Si-BNNTs: (b) Emission intensity as a function of temperature.

the emission bands are almost independent of temperature in the above range. The intensities of the peaks decrease rapidly with increasing temperature. The temperature dependence of integrated emission intensity can be fitted by the expression [Fig. 4] $]^{26}$

$$
I(T)=I_{0} /\left[1+v_{0} / v_{R} \exp \left(-\Delta E / K_{B} T\right)\right],
$$

where $I(T)$ is the integrated PL intensity at temperature $T, I_{0}$ is the intensity at $T=0 \mathrm{~K}, v_{0}$ and $v_{R}$ are the nonradiative and radiative recombination rates, respectively, and $\Delta E$ is the thermal activation energy of the nonradiative emission. The best fit to experimental data gives $\Delta E=35 \mathrm{meV}$. While the exact band structures are not clear, such small activation energy can only be related to the unpaired electron in $\mathrm{Si}$, further proving that the PL is from Si doping.

In summary, bamboo structured Si-doped BNNTs have been synthesized via catalyst-assisted pyrolysis of a polymeric precursor. Raman and FTIR techniques have been used to characterize the phonon features of the nanotubes. Both methods reveal a significant effect from $\mathrm{Si}$ dopants and bam- boo structure. Intense visible PL emission has been observed from the Si-BNNTs in the range between 500 and $800 \mathrm{~nm}$. The emission is attributed to $\mathrm{Si}$ doping. Given that $\mathrm{Si}$ is more stable than C (e.g., C can be removed by oxidation ${ }^{8}$ ), Si may have an advantage as a doping element compared to $\mathrm{C}$.

${ }^{1}$ N. G. Chopra, J. Luyken, K. Cherry, V. H. Crespi, M. L. Cohen, S. G. Louie, and A. Zettl, Science 269, 966 (1995).

${ }^{2}$ K. Suenaga, C. Colliex, N. Demoncy, A. Loiseau, H. Pascard, and F. Willaime, Science 278, 653 (1997)

${ }^{3}$ W. Q. Han, W. Mickelson, J. Cumings, and A. Zettl, Appl. Phys. Lett. 81, 1110 (2001).

${ }^{4}$ A. Rubio, J. L. Corkill, and M. L. Cohen, Phys. Rev. B 49, 5081 (1994).

${ }^{5}$ X. Blase, A. Rubio, S. G. Louie, and M. L. Cohen, Europhys. Lett. 28, 335 (1994).

${ }^{6}$ X. Blase, J. C. Charlier, A. De Vita, and R. Car, Appl. Phys. Lett. 70, 197 (1997).

${ }^{7}$ E. G. Gal'pern, V. V. Pinyaskin, I. V. Stankevish, and L. A. Chernozatonskii, J. Phys. Chem. B 101, 705 (1994).

${ }^{8}$ J. Wu, W. Q. Han, W. Walukiewicz, J. W. Ager III, W. Shan, E. E. Haller, and A. Zettl, Nano Lett. 4, 647 (2004).

${ }^{9}$ C. Zhi, Y. Bando, C. Tang, D. Golberg, R. Xie, and T. Sekigushi, Appl. Phys. Lett. 86, 213110 (2005).

${ }^{10}$ Y. Fan, Y. Wang, J. Lou, S. Xu, L. Zhang, H. Heinrich, and L. An, J. Am. Ceram. Soc. 89, 740 (2006).

${ }^{11}$ M. Weinmann, J. Schuhmacher, H. Kummer, S. Prinz, J. Peng, H. J. Seifert, M. Christ, K. Müller, J. Bill, and F. Aldingger, Chem. Mater. 12, 623 (2000).

${ }^{12}$ R. T. Paine and C. K. Narula, Chem. Rev. (Washington, D.C.) 90, 73 (1990).

${ }^{13}$ C. Tang, Y. Bando, and T. Sato, Chem. Phys. Lett. 362, 185 (2002).

${ }^{14}$ D. Golberg, Y. Bando, L. Bourgeois, K. Kurashima, and T. Sato, Appl. Phys. Lett. 77, 1979 (2000).

${ }^{15}$ R. Ma, Y. Bando, T. Sato, and K. Kurashima, Chem. Mater. 13, 2965 (2001).

${ }^{16}$ D. M. Hoffman, G. L. Doll, and P. C. Eklund, Phys. Rev. B 30, 6051 (1984).

${ }^{17}$ V. N. Popov, Phys. Rev. B 67, 085408 (2003).

${ }^{18}$ T. Kuzuba, K. Era, T. Ishii, and T. Sato, Solid State Commun. 25, 863 (1978).

${ }^{19}$ L. Wirtz, A. Rubio, R. A. de la Concha, and A. Loiseau, Phys. Rev. B 68, 045425 (2003).

${ }^{20}$ L. Wirtz, M. Lazzeri, F. Mauri, and A. Rubio, Phys. Rev. B 71, 241402(R) (2005).

${ }^{21}$ D. Sánchez-Portal, and E. Hernández, Phys. Rev. B 66, 235415 (2002).

${ }^{22}$ R. Geick, C. H. Perry, and G. Rupprecht, Phys. Rev. 146, 543 (1966).

${ }^{23}$ E. Borowiak-Palen, T. Pichler, G. G. Fuentes, B. Bendjemil, X. Liu, A. Graff, G. Behr, R. J. Kalenczuk, M. Knupfer, and J. Fink, Chem. Commun. (Cambridge) 1, 82 (2003).

${ }^{24}$ E. Rokuta, Y. Hasegawa, K. Suzuki, Y. Gamou, C. Oshima, and A. Nagashima, Phys. Rev. Lett. 79, 4609 (1997).

${ }^{25}$ L. Zhang, H. Jin, W. Yang, Z. Xie, H. Miao, and L. An, Appl. Phys. Lett. 86, 061908 (2005).

${ }^{26}$ G. Bacher, H. Schweizer, J. Kovac, A. Forchel, H. Nickel, W. Schlapp, and R. Losch, Phys. Rev. B 43, 9312 (1991). 